Article

\title{
Improving the Operational Efficiency of Parcel Delivery Network with a Bi-Level Decision Making Model
}

\author{
Daisik Nam ${ }^{1}$ and Minyoung Park ${ }^{2, *}$ \\ 1 Institute of Transportation Studies, University of California, Irvine, CA 92697, USA; daisikn@uci.edu \\ 2 Graduate School of Logistics, Inha University, Incheon 22212, Korea \\ * Correspondence: mypark@inha.ac.kr; Tel.: +82-10-3836-5070
}

Received: 1 September 2020; Accepted: 24 September 2020; Published: 29 September 2020

\begin{abstract}
This article proposes a mathematical model for integrating terminal operation strategies with shipment scheduling. We are motivated by findings from the literature on the integrated design of logistic systems. The objective of this research is to efficiently utilize the existing hub terminals and transport network by considering the minimization of costs related to terminal congestion, transport, and carbon dioxide $\left(\mathrm{CO}_{2}\right)$ emissions. Cooperative behaviors of terminal managers and fleet assignment managers are modeled in a bi-level problem framework. The total cost includes a processing cost and transport cost, and $\mathrm{CO}_{2}$ related to the assigned fleets. We introduce a terminal cost function to capture the relationship between unit processing cost with respect to hub delay, which allows us to find the minimum cost path and efficiently distribute shipments to hub terminals. The case study shows that the collaborative logistics outperforms a single routing strategy and capacity expansions in minimization of both total cost and $\mathrm{CO}_{2}$ emissions.
\end{abstract}

Keywords: parcel delivery service; collaborative logistics; hub terminals; hub delay; queuing theory; fleet assignment; $\mathrm{CO}_{2}$; smart logistics; and green logistics

\section{Introduction}

App-based mobile and online shopping services have driven the majority of the growth in the parcel delivery market. These services require logistic companies to set operationally efficient strategies to profit from the growth. Building new logistic terminals might be one solution to handle increased demand from excessive shipments arriving at terminals that lead to various logistical inefficiencies. However, land-use policies such as NIMBY (Not in my Backyard) and environmental concerns might prohibit the construction of large-scale logistic terminals. Furthermore, investing in large facilities poses significant difficulties such as municipal regulations and land prices $[1,2]$. Additionally, most capital projects require long gestation periods for decision making, administrative work, construction, and recruiting, which conflicts with the rapidly changing delivery demands. We contend that instead of investing in new logistic terminals, a smart logistic system can be more efficient by assigning trucks optimally and through terminal capacity management. Capacity planning devises the utilization of physical capacity to prevent exponentially growing shipment costs when shipment arrivals approach handling capability [3].

Industry 4.0 enables smart logistics by supporting decision making with an accurate prediction of demands and by providing flexible management [4]. The operation of hub terminals can be demand-responsive by allowing flexible handling shipments capabilities since the terminal costs are affected by terminal serves demands [3,5-8]. From the forecasted demand of a terminal, a hub terminal manager can schedule processing capability in advance by utilizing smart warehouse technologies 
embedded in a Logistics 4.0 framework. [9] includes a comprehensive review of Logistic 4.0 applications as an integrated section of Industry 4.0. Freight route decision making, which finds the best sequence of terminals for shipment movement, can also be an efficient solution to minimize the marginal effect on terminal cost [10-12]. In other words, some freight can be assigned to other terminals if a predefined hub terminal is so congested that it increases marginal costs.

The process of logistics involves complicated activities such as item collection, transport, sorting, warehouse activities, and last-mile delivery [13]. Improvements in communication and information technologies have driven the functional integration of various logistic operations, which contributes to cost reductions and service quality enhancements $[4,9,10]$. In [14], model integrating hub locations are designed with fleet assignment problems, which also incorporates a single allocation of shipments to capacitated hub locations. In [12], the holding costs of hub terminals are also included in the optimization of shipment scheduling decisions, the hub locations, and network structure. The authors of $[14,15]$ designed a decision-making model for network organization and vehicle operations by using mathematical programming.

Green logistics extends the integration of logistical operations with environmental impacts to address the global mandate of reducing greenhouse gas emissions. Heavy-duty trucks for long-haul trips and light-duty trucks for urban logistics comprise a significant portion of gas emissions [16]. In [17] a comprehensive review of research on truck emission is provided and the importance of incorporating multiple approaches such as engine technology, traffic flow regulation, and speed regulation of trucks in green logistics is discussed. In [18], a supply chain framework is proposed that adopts blockchain technology for communication and utilizes logistic information for efficient collaboration between stakeholders. Their framework is a peer-to-peer collaborative logistics, which includes a vehicle routing strategy that finds optimal routes for sustainable operations and maximizing utilization of terminal capacity.

This paper proposes a methodology to efficiently utilize existing hub terminals by minimizing congestion occurring inside them and by routing freight loads on a minimized costs path that is a sequence of terminals. In addition, if it is necessary to improve the processing efficiency of a terminal, the proposed method recommends a logistic system to improve it. By considering the minimization of total travel distance and truck trips, we also analyze the impact of the proposed method on $\mathrm{CO}_{2}$ emissions.

\section{Notation}

The following notation will be used:

\begin{tabular}{cl}
\hline$h \in H$ & hub terminal $h$ of a set of Hub terminals $(\mathrm{H})$ \\
$s \in S$ & sub terminal $s$ of a set of Sub terminals $(S)$ \\
$l \in L$ & transportation link $l$ of a set of transportation links $(L)$ \\
$a$ & terminal $a$ in total terminal set $a \in h \cup S$ \\
$x_{h}, x_{s}, x_{l}$ & the arrival rate of shipments assigned to $h, s, l$ \\
$C_{\text {max }}^{a}$ & the maximum processing rate of a terminal $a$ \\
$C_{c r i}^{a}$ & the current processing rate of a terminal $a$ \\
$C_{c r i}^{a}$ & required processing rate to process for not exceeding a predefined processing cost \\
$\Delta_{a}$ & expanded processing rate (scheduled) \\
$\Delta_{a}$ & expanded processing rate (temporary) of terminal $a$ \\
$\rho_{a}\left(x_{a}\right)$ & the density function of terminal $a$ \\
$\omega_{l}$ & maximum truckload for a truck transporting in link $l$ \\
$v_{l}$ & the number of trucks of a link $l \in L$ \\
$\operatorname{COST}_{a}\left(\rho_{a}\right)$ & Processing cost with regard to shipment density of terminal $a$ \\
$\operatorname{COST}_{l}\left(v_{l}, d_{l}\right)$ & Transportation cost of link $l$ \\
\hline
\end{tabular}




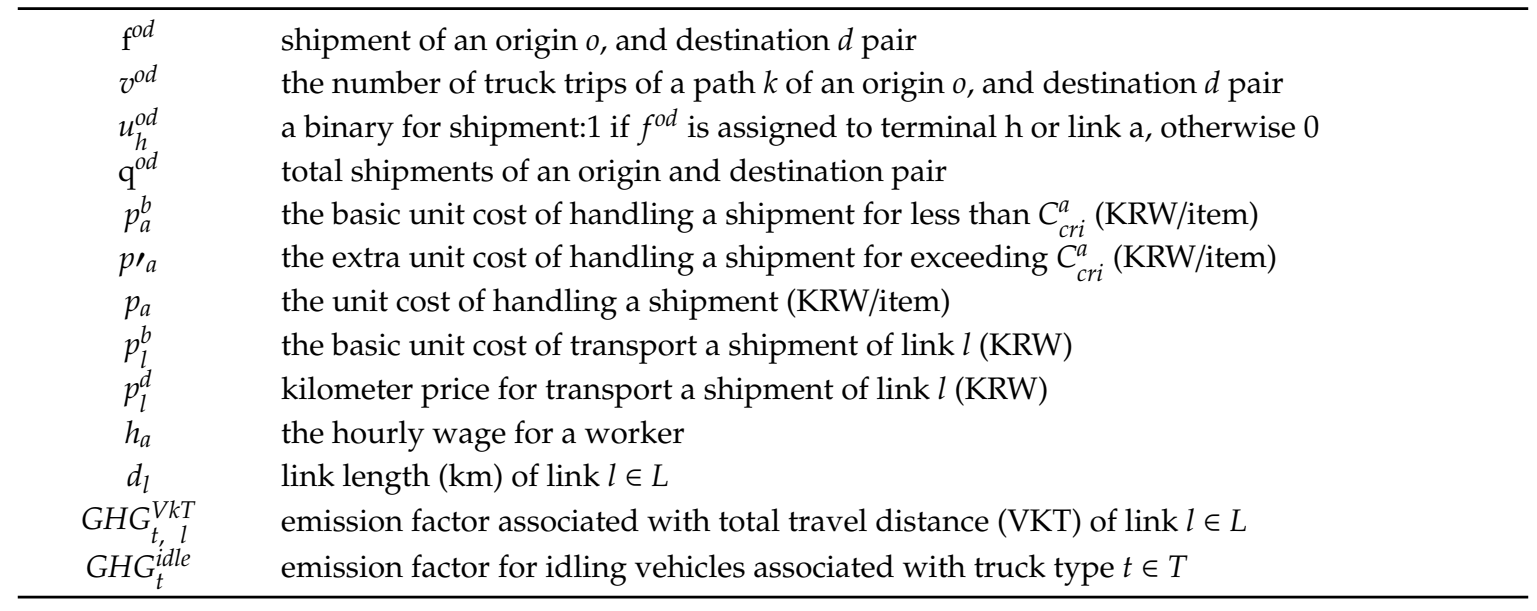

\section{Modeling Framework}

\subsection{Overview of the Modeling Framework}

The objectives of the proposed method are to minimize total cost and greenhouse emissions by optimizing processing rates of terminals and routing shipments to terminals. Figure 1 shows an example of our proposed logistic system. There are four hub terminals, four sub terminals, seven Hub-to-Hub transportation links, and eight Sub transportation links. It is assumed that the total cost consists of two parts: transportation cost and terminal cost. The transportation network between terminals includes Hub-to-Hub linehaul movements (doubled line), Hub-to-Sub movement, and Sub-to-Hub movement (single line). The transportation cost of each movement is calculated based on truck types and travel distance. For instance, a large truck (high cube trailers) has high auto operation costs per mile but a larger load. The unit transportation cost is lower for enough shipments in a truck, which is reasonable for Hub-to-Hub line haul transports shipments. Small trucks transport goods from Subterminal to Hub terminal, Sub-to-Hub, and from Sub to Sub. The processing cost of terminals is also a critical variable in our model. When the arrival rate of shipments of a terminal exceeds its processing rate, the processing cost of shipment will increase due to excessive processing time. One of the possible solutions is a reallocation of the shipments to other terminals (system optimum routing of shipments to terminals). In other words, if the terminal $\mathrm{H} 1$ is busy, assigning some shipments of subterminal A to $\mathrm{H} 3$ can reduce the congestion of $\mathrm{H} 1$ and decrease the total terminal cost. The other solution is to improve the processing rate of a terminal (i.e., H1) by increasing the number of employees or adding processing machinery, or automatic warehousing systems [19].

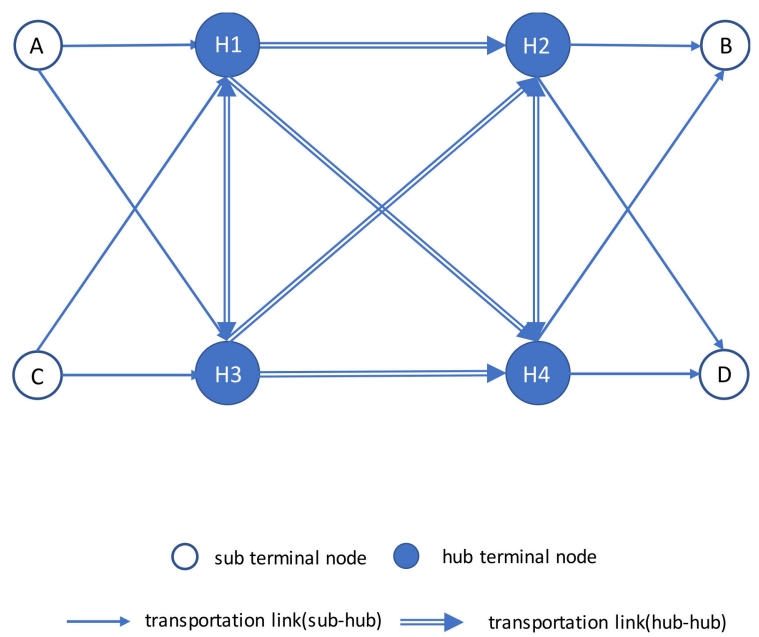

Figure 1. An Exemplary Network. 
Figure 2 describes our solution approach to the problem. The mathematical formulation is postulated as a bi-level problem. The upper problem represents the behavior of a terminal planner. The planner determines the processing rate of a terminal $\left(C_{c r i}^{a}\right)$ to minimize the total processing cost. The optimal terminal processing rates are determined by considering the limitation of terminal capacity $\left(C_{\max }^{a}\right)$, which is related to the size of a terminal, available workers, and land use. Limited space in a central business district (CBD) region is an example. The lower problem models the behavior of a shipment route manager who devises optimally routed shipments to terminals by considering terminal costs and transportation costs. The solution algorithm in the lower problem searches a minimum cost route for shipments, which is the minimized cost and greenhouse gas emissions under given demand and supplies of terminals and transportation links. The outputs of the lower problem are assigned shipments of both links and terminals. The number of shipments assigned to terminals is used to characterize the behavior of the upper problem

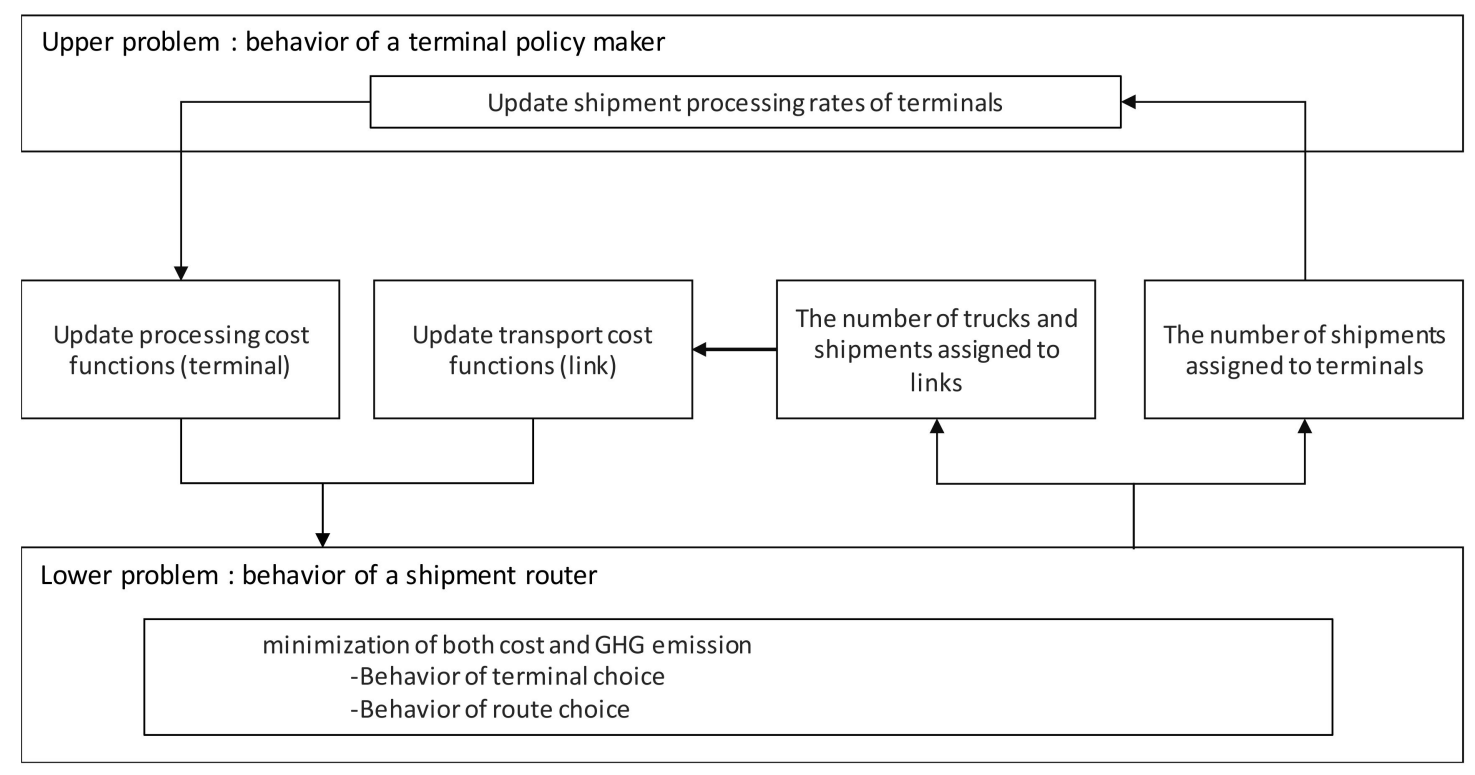

Figure 2. Overview of the Proposed Bi-Level Problem.

\subsection{Mathematical Formulation}

The mathematical formulation of the proposed model is a bi-level non-linear programming problem and is described as follows. The objective function of the upper-level problem Equation (1) represents the total cost of terminal operations to find the optimal shipment processing rate of terminals. The unit cost of shipment of a hub terminal $\operatorname{COST}_{h}$ is related to the shipment density of a terminal and derived from queuing theory. The term $f_{k}^{o d}$ is the number of shipments of path $k$ of an origin-destination pair $(o d)$, which implies that various paths exist for shipments from a single source, meaning that the shipments can be allocated to multiple hub terminals. $u_{k h}^{o d}$ is a binary associated to a hub terminal and shipments of od path $(o d, k)$ that is 1 only if shipments of od path are allocated to a hub terminal $(h)$. Constraint (2) represents the shipment density which is the number of shipments divided by the possible shipment processing rate. The term $C_{c r i}^{h}$ is the current processing rate and

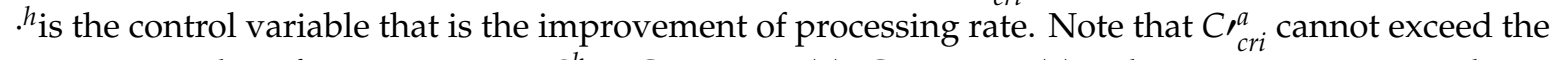
maximum value of processing rate $C_{\max }^{h}$, Constraint (3). Constraint (4) is the non-negativity condition of expanded service rate, and focuses on service rate increases. In other words, $\mathrm{C}_{c r i}^{a}$ is always equal to or larger than the service rate of the base scenario.

Once $C_{c r i}^{a}$ is computed, the lower problem assigns shipments to terminals and links. The objective function considers the total cost and greenhouse gas emission (GHG). The first sub-objective function (Equation (4)) is the formulation of finding a minimum cost path. This single pathfinding problem plans an itinerary, with consists of at least one hub terminal. For instance, shipments form a subterminal 
(origin) to another subterminal (destination) might have a route either origin (S)-hub terminal (H)-hub terminal (H)-destination (S) or S-H-S. This approach is also employed by [20] for routing shipments to capacitated hub terminals. The cost includes the terminal processing cost for hub terminals and sub terminals in addition to transportation costs.

The second sub-objective function (Equation (5)) calculates GHG by referring to EMission FACtors (EMFAC) developed by the Air Resources Board [21] in the United States. EMFAC is an official model to estimate the emission inventories of on-road mobile sources for various emission scenarios. We select Idle Emission (Idle Ex) and Running Emission (Run EX), as cities in California adopt those as the GHG reduction target in 2035, as per guidelines found in the Regional transportation Planning and Sustainable Communities Strategy (i.e., San Diego Association of Governments [22] and Southern California Association of Governments [23,24]). The coefficient of Idle Emission $\left(G H G_{t}^{\text {idle }}\right.$ ) of a truck is related to emissions during cold starts which take 10 to $20 \mathrm{~min}$ to warm up engines. The coefficient of Running Emission $\left(G H G_{t, l}^{V K T}\right)$ is the rate of $\mathrm{CO}_{2}$ of link $a$ for truck type $t$ and its unit is ton per mile. Truck type $(t)$ for a link is predetermined as either a hub link or a sub link. Truck type $t$ depends on link type $l$. The assigned trucks on a link and their travel distances characterize the total vehicle kilometers travelled ( $V K T_{t}^{l}$ ) of link $l$ operated by truck type $t$. The link in Constraint (6) shows assigned shipments on a terminal or transportation link. Constraint (7) converts the number of trips on a link $l\left(v_{l}\right)$, which always rounds up a number to the smallest integer value greater than the number. Constraint (8) is the total number of shipments constraint for $o-d$ paths. Constraint (9) is related to the density of shipments of a terminal. Constraint (10) is non-negativity of a path flow $f_{k}^{r s}$. VKT $T_{t}^{l}$ for GHG emission is computed by Constraint (11).

(Upper problem)

$$
\underset{C_{c r i}^{a}}{\operatorname{argmin}} \sum_{h \in H} \operatorname{COST}_{h}\left(\rho\left(x_{h}\right)\right) \sum_{o d} f^{o d} u_{h}^{o d}
$$

subject to

$$
\begin{gathered}
\rho\left(x_{h}\right)=\frac{x_{a}}{C_{c r i}^{h}+\Delta^{h}} \\
C_{c r i}^{\prime h}=C_{c r i}^{h}+\Delta^{h} \leq C_{\text {max }}^{h} \forall \mathrm{h} \in \mathrm{H} \\
\Delta^{h} \geq 0 \forall h \in \mathrm{H}
\end{gathered}
$$

(Lower Problem)

$$
\begin{gathered}
\min f 1=\sum_{h \in H} x_{h} \operatorname{COST}_{h}\left(\rho_{h}\left(x_{h}\right)\right)+\sum_{s \in S} x_{s} \operatorname{COST}_{s}\left(\rho_{s}\left(x_{s}\right)\right)+\sum_{l \in L} v_{l} \operatorname{COST}_{l}\left(v_{l}\right) \\
\min f 2=\sum_{t \in T} G H G_{t}^{\text {idle }}+\sum_{l \in L} G H G_{t, l}^{V K T} * V K T_{l, t}
\end{gathered}
$$

subject to

$$
\begin{gathered}
x_{a}=\sum_{o d} f^{o d} u_{a}^{o d} \forall o d, a \in H \cup S \cup L \\
v_{l}=\sum_{o d} \sum_{l}\left\lfloor 1, x_{l} / \omega_{l}\right\rfloor u_{l}^{o d} \\
\forall o d, l \in L \\
x_{a} \geq 0 \\
\forall a \in H \cup S \cup L \\
\rho_{a}\left(x_{a}\right)=x_{a} / C^{a}{ }_{c r i} \\
\forall a \in H \cup S \\
V K T_{t}^{l}=v_{l} * d_{l} \\
\forall l \in L
\end{gathered}
$$




\subsection{Cost Functions}

The underlying assumption of the mathematical formulation is that there is an increased processing cost at a terminal if the arrival rate of shipments exceeds a terminal's processing rate $\left(C_{c r i}^{a}\right)$. In other words, shipments' processing cost per unit depends on the shipment density and processing capability of a terminal. This study derives the unit terminal processing cost from $\mathrm{M} / \mathrm{M} / 1$ queuing theory, which estimates the average wait time from an arrival rate of shipments and a service (processing) rate of a server (hub terminal), based on the assumptions that a random arrival rate follows the Poisson distribution and the service adopts the first-come-first-served (FCFS) protocol. Other random arrival distributions such as normal distribution may exist. Nevertheless, we apply the Poisson that allows us to design a simple mathematical model, referring to $[2,3,5,25]$. We define $\rho_{a}$ as the density of shipments of terminal $a$, which is the ratio of shipments arrival rate $\left(x_{a}\right)$ divided by the critical processing rate $\left(C_{c r i}^{a}\right)$, Equation (12). In queuing theory, $C_{c r i}^{a}$ is considered as a service rate, which represents the number of items per hour processed by a server. From $\rho_{a}$ and $x_{a}$, we can estimate the average wait time $W_{a}$, derived from the well-known Little's Formula [26], Equation (13).

$$
\begin{aligned}
& \left.\rho_{a}\left(x_{a}\right)=x_{a} / C_{c r i}^{a}\right) \\
& W_{a}=\frac{\rho_{a}}{x_{a}\left(1-\rho_{a}\right)}
\end{aligned}
$$

We define $W_{a}$ as the fixed value $\mathrm{W}$, which is the target operation hour of handling shipments. Our interest is to calculate the desired waiting time criterion of the service rate for terminal $a\left(C_{c r i}^{a}\right)$ that allows shipment processing time not to exceed the criterion (e.g., 1 hour). Then, we consider $C_{c r i}^{\prime a}$ as an updated variable of $C_{c r i}^{a}$ to serve $x_{a}$ in the desired waiting time. By converting Equation (13) into a quadratic form (Equation (14)) in terms of $C_{c r i}^{\prime a}$, we can find the required processing rate to handle arriving shipments at a given time, as Equation (15).

$$
\begin{gathered}
W_{a}\left(C \prime_{c r i}^{a}\right)^{2}-W x_{a} C \prime_{c r i}^{a}-x_{a}=0 \\
C_{c r i}^{a}=\frac{W x_{a}+\sqrt{\left(W x_{a}\right)^{s}+4 W x_{a}}}{2 L_{a}}
\end{gathered}
$$

Figure 3 indicates the average waiting time according to the arrival rate of shipments $\left(x_{a}\right)$ and the processing rate $\left(C_{c r i}^{a}\right)$. Let us assume that a terminal can process shipments at a rate of 650 items per hour. When the arrival rate of shipments approaches the current processing rate $C_{c r i}^{a}$, the average waiting time of a shipment increases rapidly. If the arrival rate is higher than the processing rate, the possible solution is to increase the processing rate to handle the shipments in time. The dashed lines are examples of an average waiting time with respect to the shipment arrival rates. The intersection points between the black line at 1 hour wait time and the dashed line indicate the required processing rate to handle the shipments at the arrival rate of associated $x$ points. For instance, to handle 770 shipments per hour in less than an hour, a processing rate $\left(\mathrm{C}_{c r i}^{a}\right)$ of 780 boxes per hour is required.

Variable processing rates imply that a service manager can control the processing time by increasing the temporary service rate at the amount of $\Delta / \mathrm{s}$ if the shipments arrival rate at a terminal is beyond the maximum processing rate $\left(C_{c r i}^{a}\right)$. However, handling shipments beyond the scheduled processing rate may bring additional costs $\left(p^{\prime} a\right)$ due to several factors such as demurrage, unskilled servers, insufficient sorting machine, and overtime allowance, as indicated in Equation (17), which increases the total processing cost at a terminal, Equation (16). Additional cost due to the excessive demand can be estimated by the average hourly wage $\left(h_{a}\right)$ over the processing rate of unscheduled works $\Delta{ }^{\prime}$.

$$
\text { total processing cost }=p_{a}^{b} \times \min \left(C_{c r i}^{a}, x_{a}\right)+p_{a}^{\prime} \times \max \left(0, C_{c}^{a}{ }_{c r i}-C_{c r i}^{a}\right)
$$


where

$$
p^{\prime}{ }_{a}=h_{a} / \Delta{ }_{a}
$$

From the total processing cost and the associated arrival rate, we can also estimate the unit cost of processing as Equation (18).

$$
\text { unit cost, } \mathrm{p}_{\mathrm{a}}=\frac{\text { total cost }}{x_{a}}
$$

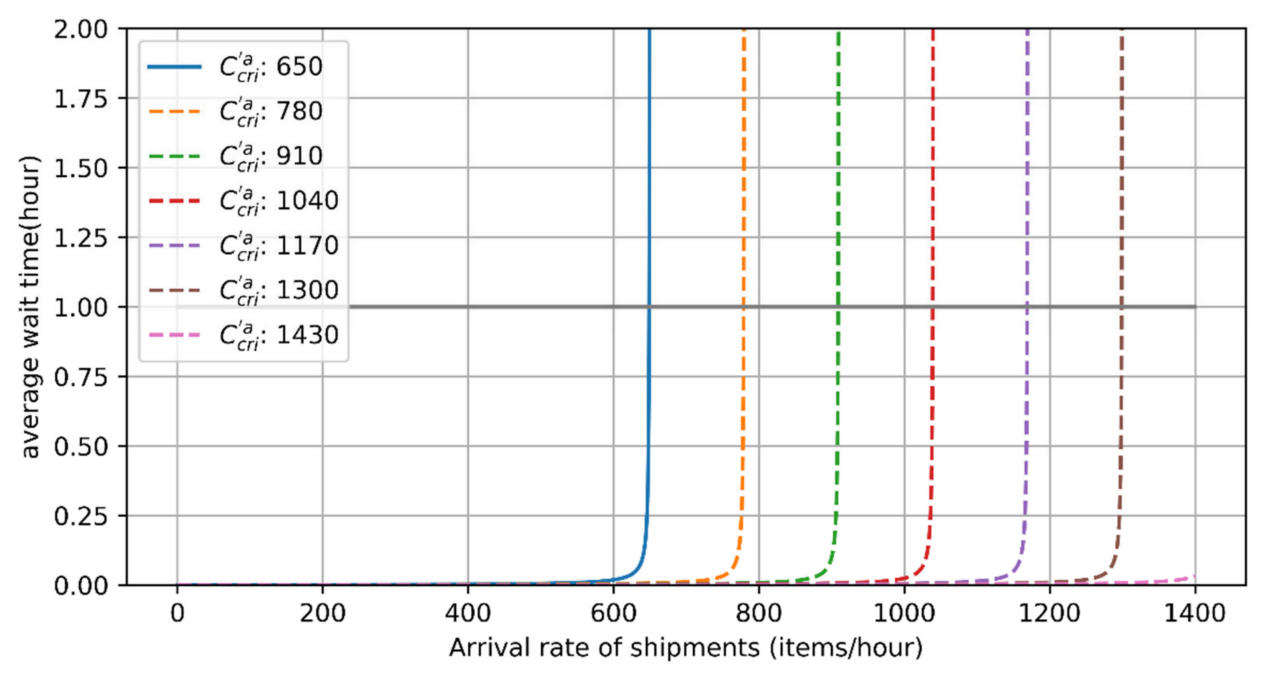

Figure 3. The Average Waiting Time According to the Arrival Rate of Shipments $\left(x_{a}\right)$ and the Processing Rate $\left(C_{c r i}^{a}\right)$.

Figure 4 indicates how exceeded demands affect the unit shipment costs with respect to the processing rate of unscheduled work $\left(\Delta^{\prime} a\right)$. The processing rate of scheduled work $\left(\Delta_{a}\right)$ is assumed to 130 boxes per hour for the figure. If $\cdot / a$ is the same with the processing rate of $\cdot$, the unit cost of handling shipment does not change. However, a lower $/_{a} a$ increases the unit cost. The unit cost is a non-linear and non-convex function with respect to the arrival rate of shipments, therefore, it is impossible to have a global optimum solution for the mathematical problem with this function. Thus, we approximate the function into a piecewise linear function, which has the same mechanism as the rectified linear activation function, also known as ReLU. If an arrival rate of shipments is less than the critical service rate, the unit cost of terminal processing is a base rate. Otherwise, a processing cost increases linearly, as shown in Equation (19). $\pi$ is empirically determined from our experiments based on Equation (16).

$$
\operatorname{COST}_{a}=\mathrm{c}_{\mathrm{a}}+\max \left(0,\left(x_{a}-C_{c r i}^{a}\right) \times \pi\right)
$$

This function is not able to guarantee a solution because of the non-differentiable point at $C_{c r i}^{a}$. However, the gradient descent method-based heuristic solutions can solve the problem by regulating the derivative at the point. Furthermore, the probability to fall into the exact non-differentiable point is very small [27].

The transportation cost consists of basic cost $\left(p_{l}^{b}\right)$ and the kilometer cost $\left(p_{l}^{d}\right)$. There are transportation cost differences between Hub-to-Hub link and Sub-to-Sub link. Linehaul trucks of Hub-to-Hub transport assumed to be 11-ton high cube trailer, carry larger shipments than trucks for Sub-to-Sub link (5-ton box truck). Consolidating shipments inside a Hub terminal reduces the unit transportation cost of a shipment. However, larger trucks are only efficient when enough shipments are loaded. If the number of shipments between hub terminals are lower than our criterion, we assume that smaller trucks (5-ton box trucks) transport those shipments. For the Sub-to-Hub and Sub-to-Hub links, it is assumed that 5 -ton box trucks are used. Similarly, if links connected to subterminals have 
shipments lower than a truckload, unit transportation cost might be higher than full-load, which assume that twice of both $p_{l}^{b}$ and $p_{l}^{d}$

$$
\operatorname{COST}_{l}\left(v_{l}, d_{l}\right)=\left\{\begin{array}{l}
p_{l}^{b}+p_{l}^{d} \times d_{l} \text { if } v_{l} \geq \omega_{l} \\
p_{l}^{\prime}{ }_{l}+p_{l}^{\prime} \times d_{l} \text { otherwise }
\end{array}\right.
$$

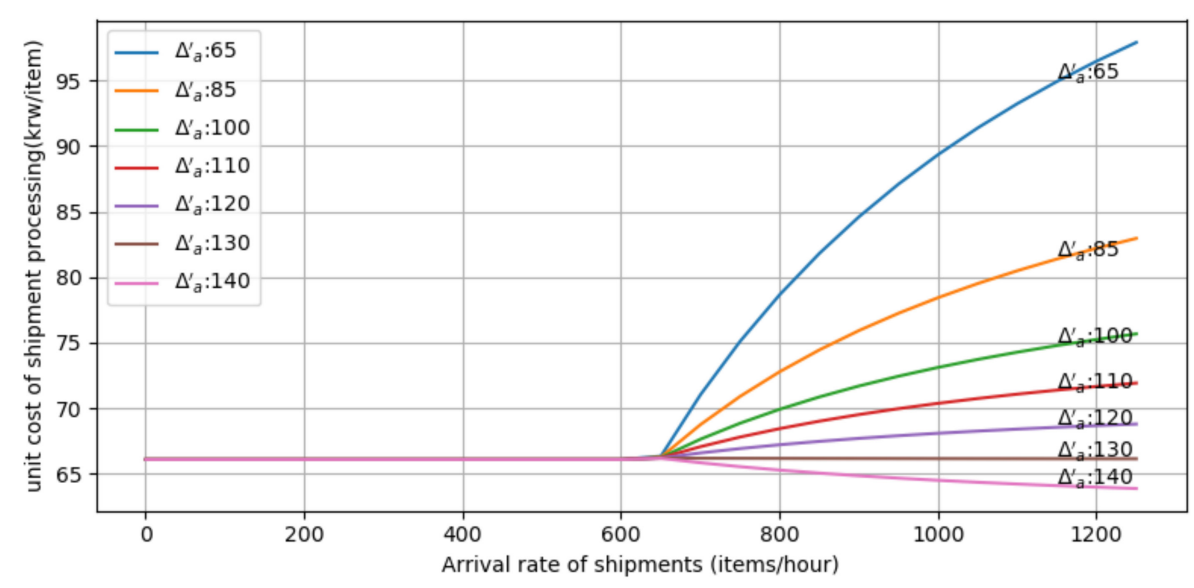

Figure 4. Unit Cost of Shipment Processing With Respect to the Processing Rate of Unscheduled Work.

\section{Solution Algorithm}

The proposed bi-level mathematical programming formulation is a non-convex problem, and the constraint set and the objective function are non-differentiable. However, the objective function and constraints are linear and differentiable. Note that even bi-level linear programming is an NP-Hard problem [28,29] and solving the proposed model is a challenging task. Converting mathematical programming into a graph helps to solve the problem. Figure 5 shows an example of the graph representation of the logistic system. There are four terminals (two terminals and two hubs) and three transportation links in the example. To consider the increased cost due to excessive demand, we also disaggregate a terminal node into a set of sub-nodes and a link, which is a simple schematic format of the processing flow of a logistic terminal as used in [3,7]. For instance, we convert the Hub 1 (H1) node into a link with a node for inflow $\left(\mathrm{H} 1_{\text {in }}\right)$ and a node for outflow $\mathrm{H} 1_{\text {out }}$, we use a tuple for a link $\left(\mathrm{H} 1_{\text {in }}, \mathrm{H} 1_{\text {out }}\right)$. Although the computational complexity increases due to the increased number of nodes, this representation enables us to find a path for minimizing total cost with dynamic costs for terminal processing and transportation simultaneously. Shipments origin from in-node $\left(\mathrm{A}_{\text {in }}\right)$ and pass through a processing link of subterminal (link 1 ) for transportation, as indicated in Figure 5. Shipments travel on links from 2 to 6 and arrive at the in-node of terminal $B\left(B_{i n}\right)$.

Figure 6 illustrates our graph representation of Figure 1. A node for sub terminals is connected to hub terminals and is not permitted for direct transportation between sub terminal nodes, which reflects current logistic systems of the case study. Hub nodes are mutually connected with hub links. Back to the example of Figure 1, shipments having route (A-H1-H4-D) will be rerouted when the processing cost of a link $\left(\mathrm{H} 1_{\mathrm{in}}, \mathrm{H} 1_{\text {out }}\right)$ is so high due to excessive shipments to process that detouring to $\mathrm{H} 3$ is cheaper.

The lower problem assigns the demand of hub terminals based on the minimum cost paths. Since the transport cost is based on basic cost and distance cost according to fleet types and travel distance, we can also minimize the second objective function simultaneously. Due to the unknown unit of monetized gas emission value and computational complexity, we regard the number of fleet trips and travel distances of the associated trucks as a proxy for greenhouse gas emissions. Then the upper problem updates the critical processing rate $C_{c r i}^{a}$ by increasing expanded processing rate $\left(\cdot{ }_{a}\right)$ that lowers the processing cost for excessive demand of a terminal, Equation (21). The value of ${ }_{\mathrm{a}} \mathrm{d}$ during 
the current iteration is determined by the difference between the assigned shipment $x_{a, i}$ of the current iteration and base critical processing rate $\left(C_{c r i, 0}^{a}\right)$, as shown in Equation (22). There is a scalar step-size modifier $\alpha$ that ranges from 0 to 1 for maintaining the feasibility of the search direction. From our experience, we select 0.02 .

$$
\begin{gathered}
C_{c r i, i}^{a}=C_{c r i, 0}^{a}+\Delta_{\mathrm{a}, \mathrm{i}} \\
\Delta_{\mathrm{a}, \mathrm{i}}=\alpha \times \max \left(0, x_{a, i}-C_{c r i, 0}^{a}\right)
\end{gathered}
$$

The iterative process continues until there is no improvement in the value of the objective function.

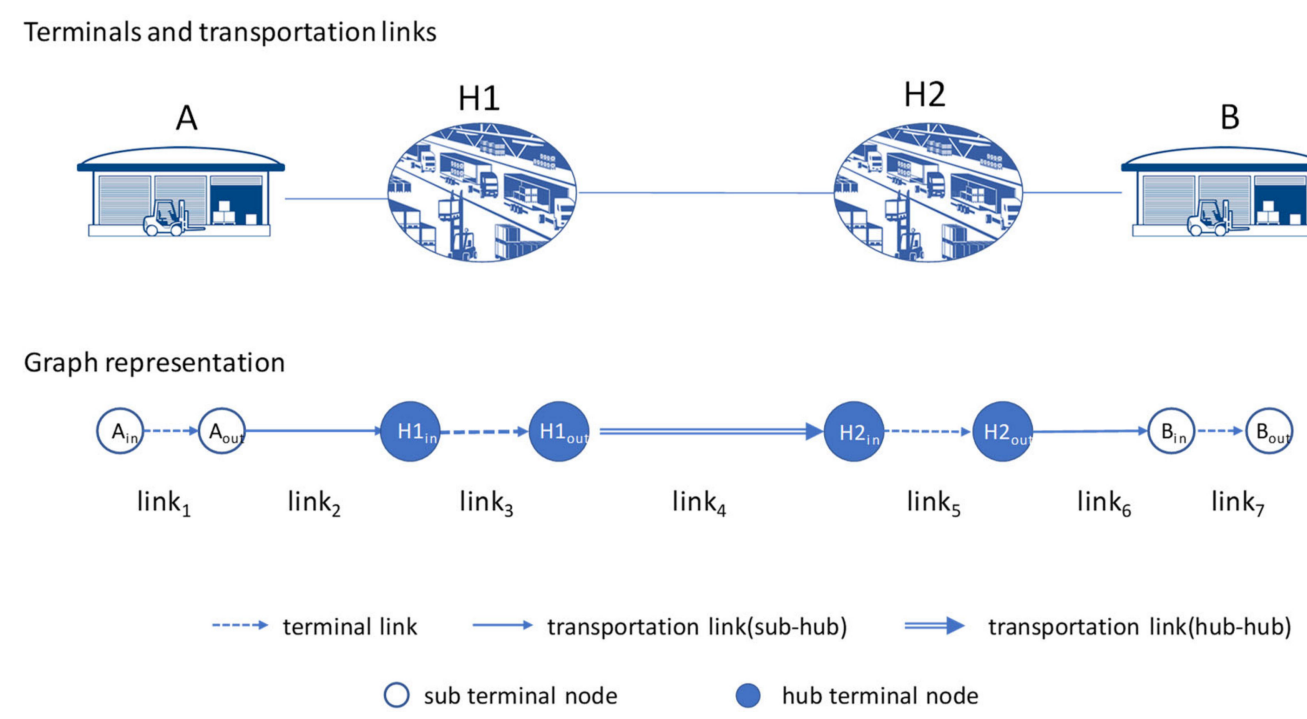

Figure 5. An Example of the Graph Representation of the Logistic System.

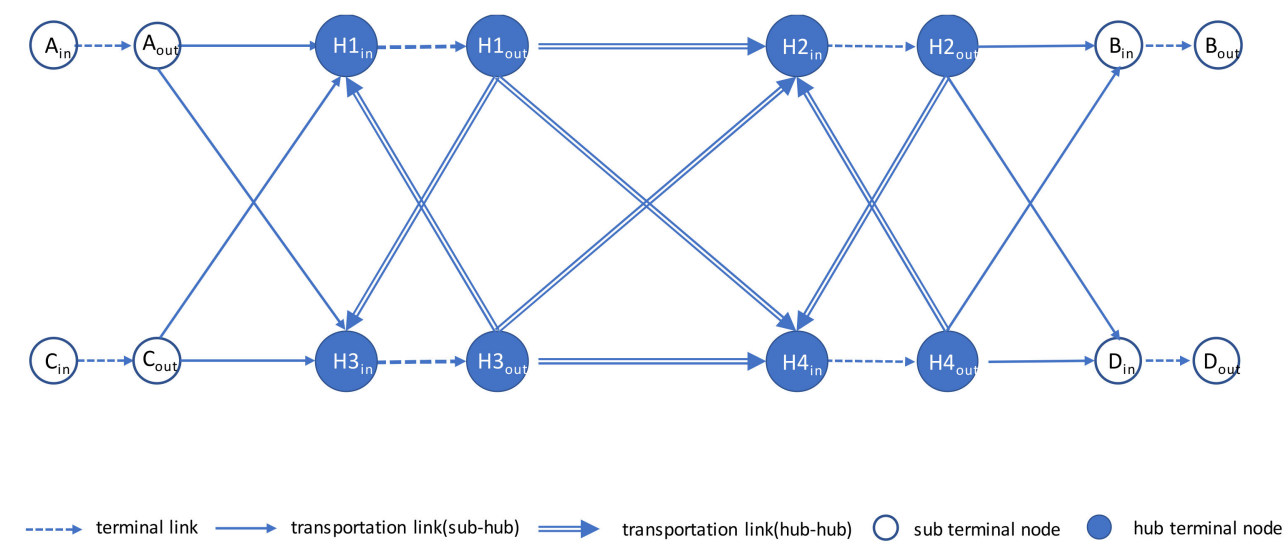

Figure 6. The Graph Representation of the Proposed Method.

\section{Case Study}

The proposed model is applied to a parcel delivery logistic system in Korea, which is shown in Figure 7. There are 9 hub terminals and 213 sub terminals. We used an actual road network shown in in Figure 7a to calculate travel distances of the shortest time path between terminals. Figure $7 \mathrm{~b}$ is an abstract representation of the network, used in the mathematical formulation. The green line represents a line haul transportation link between hubs and the gray line indicates a link from hub to sub and sub to hub that are currently used as sub-hub terminal relationships. The links (dashed gray line) recharacterize the relationship between sub and hub terminals to minimize total cost, as shown in Figure 7. In addition, the abstract network also includes the processing link of terminals. 


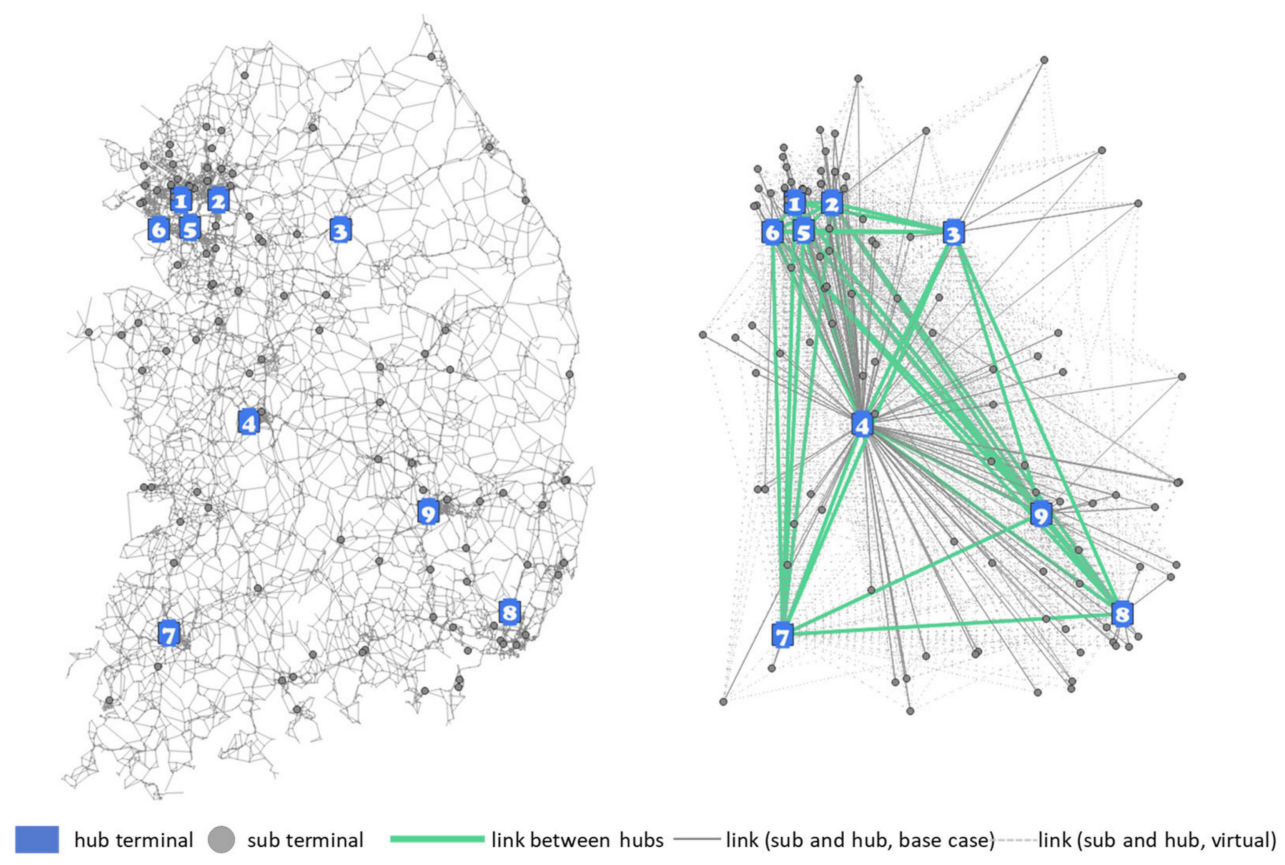

(a) actual road network and Terminals

(b) Abstracted logistic network

Figure 7. Overview of Terminal Locations and Network of the Case Study. (a) Actual road network and Terminals; (b) Abstracted logistic network.

The parameters used in the case study are shown in Table 1. From the obtained actual operational data, we select three types of shipment costs. Eleven-ton high cube trailers can carry shipments between hub terminals up to 1400 boxes with a basic cost of $79.6 \mathrm{KRW}$ and distance-based price of $0.38 \mathrm{KRW}$. It is assumed that 5-ton box trucks transport shipments between hub and sub terminals. The truckload of a 5-ton truck is assumed to be 550 boxes. The dataset also indicates if a sub is connected to a hub terminal, as shown in Figure $7 \mathrm{~b}$. The costs of shipment processing in a terminal is estimated based on the obtained data and our assumptions. The basic processing cost is $75 \mathrm{KRW}$ and $\pi$ is estimated from the minimum hourly wage $\left(h_{a}, 8,590 \mathrm{KRW}\right)$ and the processing rate of unscheduled condition $\left(\Delta^{\prime} a\right)$. $\Delta^{\prime} a$ is assumed as $50 \%$ of the regular processing rate. To calculate greenhouse gas emissions, we employ emission coefficients for trucks in EMPAC 2017. $\mathrm{CO}_{2}$ Run Exhaust is calculated from the total travel distance. Moreover, emissions regarding idling (Idle Exhaust) are based on the number of trips.

Table 1. Parameters of the Case Study.

\begin{tabular}{|c|c|c|c|c|c|}
\hline Cost Type & Parameters & $\begin{array}{l}\text { Basic Cost } \\
\text { (KRW/Box) }\end{array}$ & $\begin{array}{c}\text { km Price } \\
\text { (KRW/Box/km) }\end{array}$ & $\begin{array}{l}\text { Truckload } \\
\text { (Box/Truck) }\end{array}$ & $\begin{array}{l}\text { Low Demand } \\
\text { Penalty }\end{array}$ \\
\hline \multirow{4}{*}{ Transport cost } & $\begin{array}{l}\text { sub-hub, hub-sub } \\
\text { (current) }\end{array}$ & 132.9 & 0.53 & 550 & $2 x$ \\
\hline & $\begin{array}{l}\text { sub-hub, hub-sub } \\
\text { (not current) }\end{array}$ & 199.4 & 0.79 & 550 & $2 x$ \\
\hline & hub-hub & 79.6 & 0.38 & 1400 & hub-sub cost \\
\hline & Parameters & \multicolumn{2}{|c|}{ Basic cost } & \multicolumn{2}{|c|}{$\begin{array}{l}\text { After capacity } \\
(\text { per box }, \pi)\end{array}$} \\
\hline \multirow{5}{*}{ Terminal cost } & processing cost (hub) & \multicolumn{2}{|c|}{$75 \mathrm{KRW}$} & \multicolumn{2}{|c|}{$0.02 \mathrm{KRW}$} \\
\hline & processing cost (sub) & \multicolumn{2}{|c|}{$75 \mathrm{KRW}$} & \multicolumn{2}{|c|}{$0.02 \mathrm{KRW}$} \\
\hline & working hour & \multirow{2}{*}{\multicolumn{2}{|c|}{$\begin{array}{c}8 \mathrm{~h} \\
0.15\end{array}$}} & & \\
\hline & processing margin & & & & \\
\hline & & \multicolumn{2}{|c|}{$\mathrm{CO}_{2}$ Run Exhaust (ton $/ \mathrm{km}$ ) } & \multicolumn{2}{|c|}{$\mathrm{CO}_{2}$ Idle Exhaust (ton/trip) } \\
\hline Greenhouse Gas & Hub-to-Hub & \multicolumn{2}{|c|}{0.002664} & \multicolumn{2}{|c|}{0.00446} \\
\hline Emission $\left(\mathrm{CO}_{2}\right)$ & sub-hub, hub-sub & \multicolumn{2}{|c|}{0.001001} & \multicolumn{2}{|c|}{0.000156} \\
\hline
\end{tabular}


Table 2 describes the baseline conditions and assumptions of hub terminals. This study refers to the capacity of hub terminals of [30], but the terminal index is encrypted. We infer the capacity of hub terminals according to the assigned shipments from origin-destination demands (1.09 daily million shipments, and 9.452 od pairs) and its route information. This study converts the daily unit of demand and terminal capacity into hourly rate and demand based on the underlying working hour assumption ( $8 \mathrm{~h}$ per day). The base processing rate is assumed as $85 \%$ of the maximum processing rate ( 0.15 processing margin shown in Table 1 ). The shipment arrival rate of the base case is computed from the hierarchical relationship between sub and hub terminals, which also affects processing cost from Equation (19).

Table 2. The Baseline Conditions and Assumptions of Hub Terminals.

\begin{tabular}{ccccc}
\hline Terminal ID & $\begin{array}{c}\text { Base Processing } \\
\text { Rate (Box/Hour) }\end{array}$ & $\begin{array}{c}\text { Maximum Processing } \\
\text { Rate (Box/Hour) }\end{array}$ & $\begin{array}{c}\text { Shipments Arrival } \\
\text { Rate (Box/Hour) }\end{array}$ & $\begin{array}{c}\text { Processing Cost } \\
\text { (KRW/Box) }\end{array}$ \\
\hline 1 & 28,258 & 32,500 & 43,717 & 384.2 \\
2 & 50,865 & 58,500 & 48,901 & 75.0 \\
3 & 7870 & 9051 & 4990 & 75.0 \\
4 & 63,581 & 73,125 & 56,610 & 75.0 \\
5 & 9184 & 10,563 & 10,882 & 109.0 \\
6 & 14,129 & 16,250 & 16,110 & 714.6 \\
7 & 6358 & 7312 & 2677 & 158.0 \\
8 & 14,553 & 16,738 & 18,742 & 78.0 \\
\hline
\end{tabular}

Figure 8 indicates the distribution of origin-destination shipments. Figure 8 a represents the entire origin and destination demand, which indicates that a significant portion of shipments is associated with the Seoul Metropolitan Area (SMA). Busan, Daejeon, and Gwangju also have a large number of shipments, most of which also relate to SMA.

We analyze the proposed model by comparing it with other strategies in addition to the base case (Table 3). Scenario 1 is a strategy only focusing on improving processing rate at allocated shipments if it exceeds the processing rate of the base case. In other words, this strategy minimizes the total terminal costs by updating processing rates while satisfying the maximum processing rate constraint in the upper problem of the proposed mathematical formulation. Scenario 2 only devises a minimum cost routing strategy under the given processing rates of the base case. Scenario 3 includes the complete problem by considering both Scenarios 1 and 2 simultaneously.

Table 3. Scenarios for the Comparative Analysis.

\begin{tabular}{ccc}
\hline Scenario & Strategy & Formulation \\
\hline Scenario 1 & Processing rate improves & upper problem \\
Scenario 2 & Routing strategy (minimum cost path) & lower problem \\
Scenario 3 & All strategies & bi-level problem \\
\hline
\end{tabular}

Figure 9 shows assigned shipments to transport links for the base case and the proposed method. Figure 9a visualizes the base case, which indicates that terminal 4, located in Daejeon, plays an important role as a hub terminal. $32.3 \%$ of total shipments are handled through the hub terminal 4 in the base case. Our proposed method (Scenario 3) assigns $42.7 \%$ of shipments to hub terminal 4, implying the overall design of the logistic system more likely to be a hub-and-spoke system. In addition, Figure $9 \mathrm{~b}$ describes that the optimized logistic system connects shipments from local sub terminals to near a hub terminal that is not busy to minimize transportation cost and utilize the capacity of hub terminals efficiently. More sub-hub links connecting to Hub Terminals 7, 8, and 9 exist in the proposed method than the base case. Links having shipments less than a truckload induces higher 
transport costs. The proposed method consolidates those shipments to adjacent local hub terminals, then transport to other hubs. These results are consistent with the routing design of $[30,31]$.

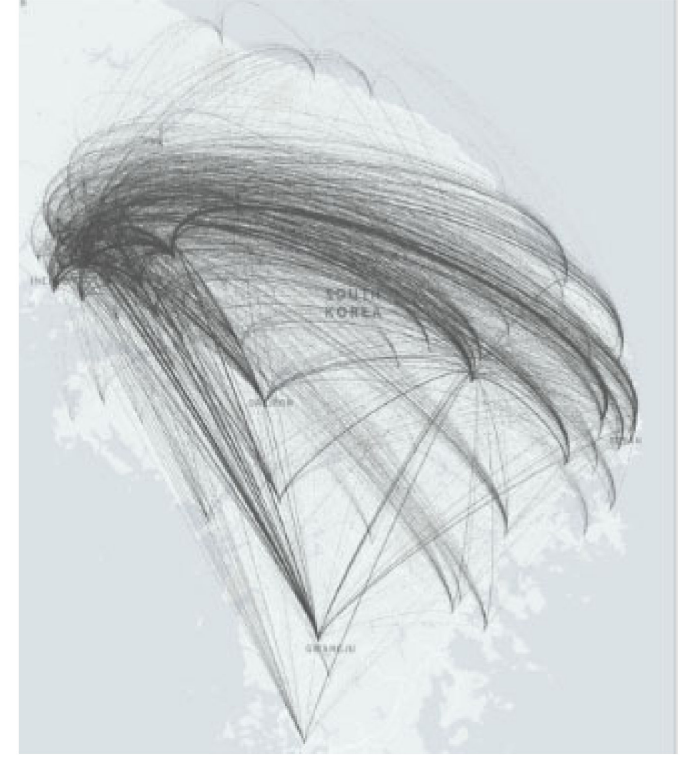

(a)

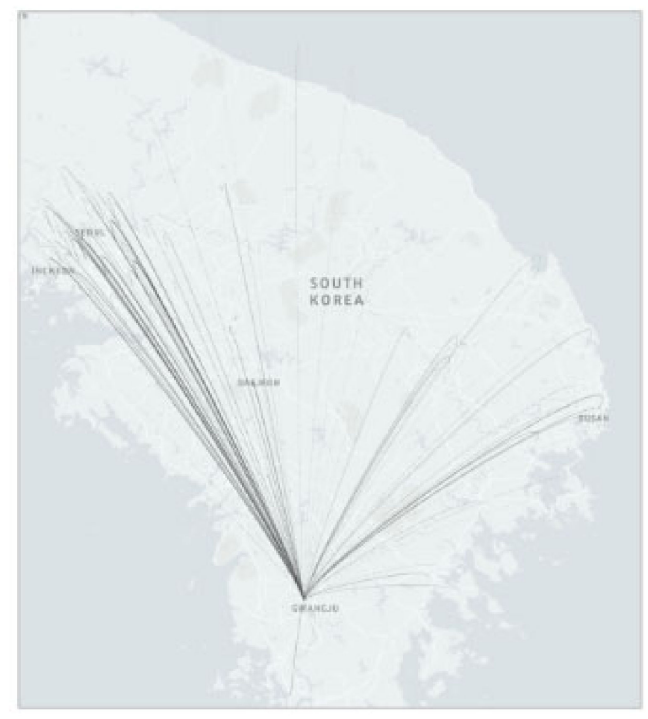

(c)

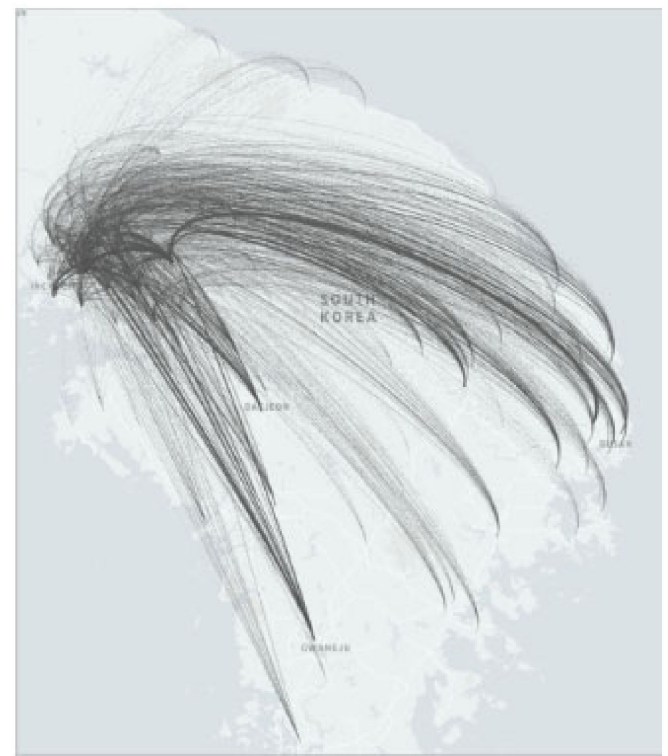

(b)

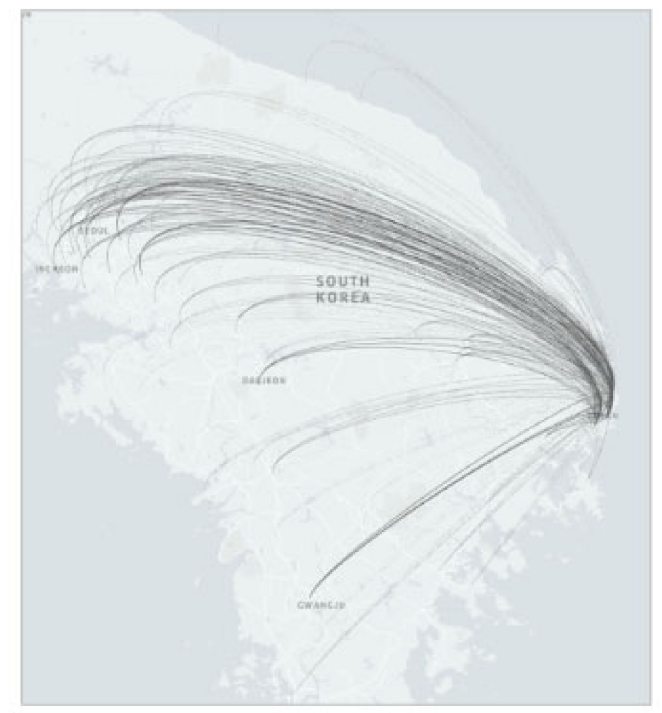

(d)

Figure 8. The Spatial Distribution of Origin-Destination Shipments. (a) Shipments OD volumes of Korea (b), Shipments from Seoul Metropolitan Area, (c) Shipments origin from Gwangju Metropolitan city, (d) Shipments origin from Busan Metropolitan city.

Figure 10 shows the results of the total cost of each scenario. The proposed method reduces the total cost from 93.7 KRW to 82 million KRW per operation hour. Most of the improvements in the total terminal cost come not only from the enhancement of the processing rate of selected terminals but also from the terminal selections. The proposed method allocates shipments to less congested terminals, thus ensuring that it utilizes the supply of terminals efficiently. Scenario 2 also decreases the total terminal cost by increasing the processing rate. Although Scenario 3 also improves the efficiency of the logistic system, applying only the routing strategy (Scenario 3) increases the total transport cost since some shipments are assigned to less congested terminals, thereby inducing longer travel distances. The routing strategy only finds a single route that is a minimum cost under the link conditions of 
terminal and transport. Besides, the sole routing strategy cannot guarantee the equilibrated solution: thus, the updated route may or may not induce congestion of the selected terminal, which cannot improve the efficiency of the logistics system effectively.

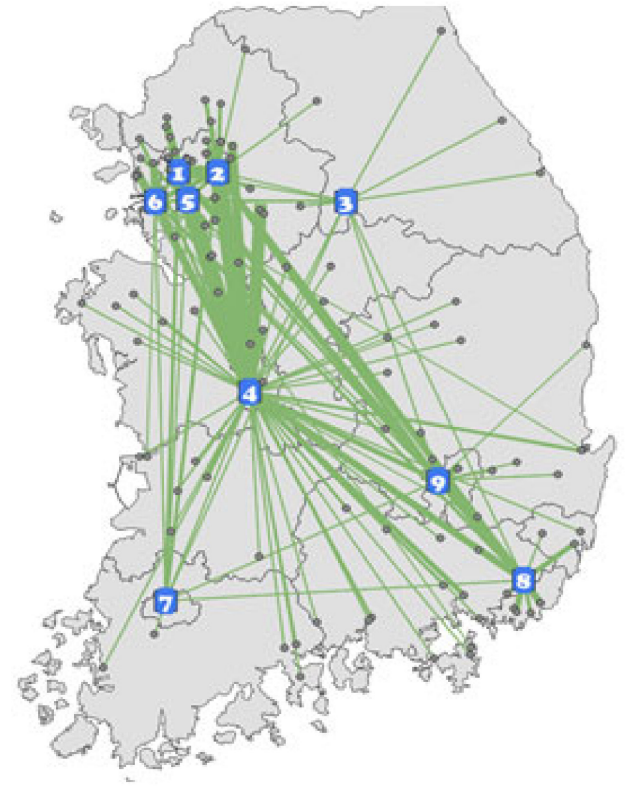

(a)

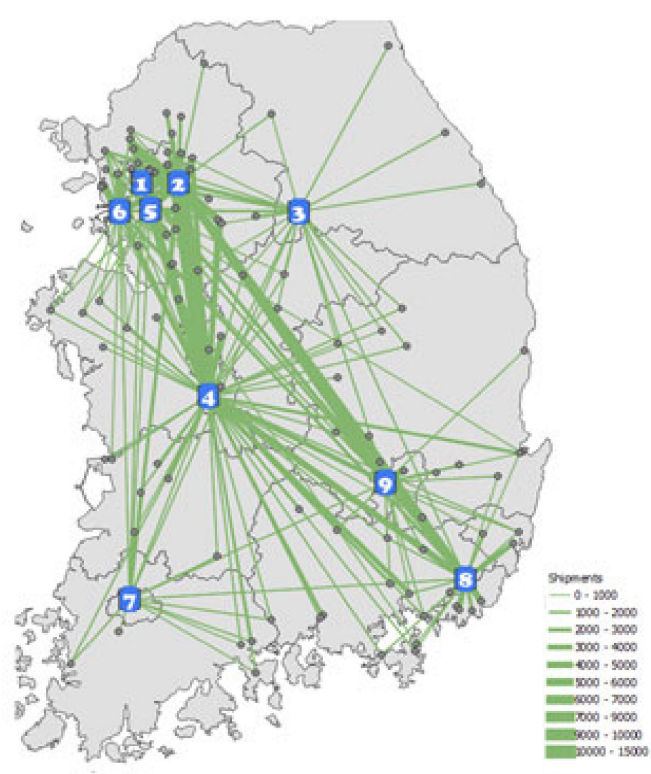

(b)

Figure 9. The Result of Assigned Shipments to Transport Links. (a)Base Case, (b) Proposed Method (Scenario 3).

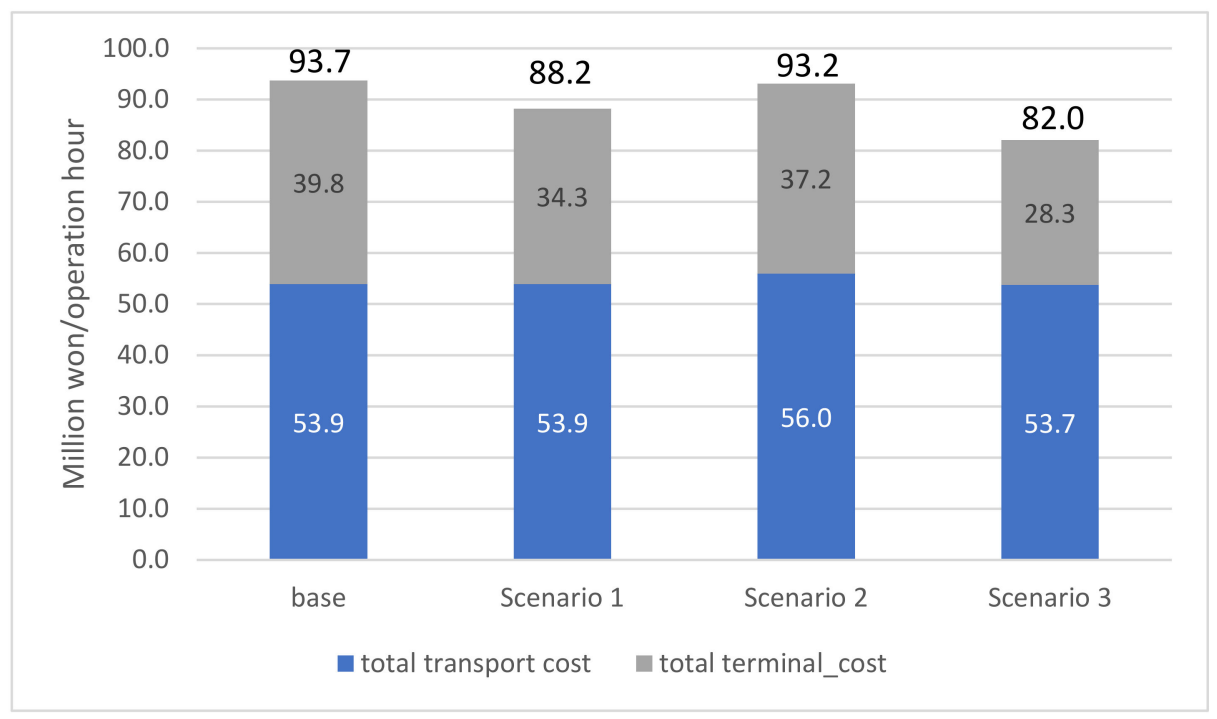

Figure 10. Comparison of The Total Costs From The Scenario Results.

Table 4 shows the details of the results of the hub terminals. Scenario 3 distributes the shipments over the hub terminals. It is noteworthy that only improving the processing rate could not decrease the unit processing cost due to the maximum processing rate constraints. This requires the logistic system manager to devise a routing strategy. However, Scenario 2 cannot effectively reduce the unit processing cost, either. Incorporating both improved service rates and routing strategies can decrease the unit cost meaningfully (Scenario 3). The reduced number of shipments lowers the processing cost of hub terminal 1 to $75 \mathrm{KRW} / \mathrm{box}$. The number of shipments of hub terminal 1, where the processing cost is the highest processing in the base case, decreases to 24,321 boxes from 43,717 under the maximum 
service rate $(32,500$ boxes per hour) which is bounded to the maximum processing rate. However, hub terminal 2's shipments increase from 48,901 boxes to 62,649; this is because even increased cost could save the total cost passing hub terminal 2.

Table 4. The Details of the Results of the Hub Terminals.

\begin{tabular}{|c|c|c|c|c|c|c|c|c|c|}
\hline \multirow[t]{2}{*}{ HUB ID } & \multicolumn{3}{|c|}{$\begin{array}{l}\text { Shipments Arrivals } \\
\text { (Boxes/Hour) }\end{array}$} & \multicolumn{3}{|c|}{$\begin{array}{l}\text { Processing Rate } \\
\text { (Boxes/Hour) }\end{array}$} & \multicolumn{3}{|c|}{$\begin{array}{c}\text { The Unit Processing Cost } \\
\text { (KRW/Box) }\end{array}$} \\
\hline & Scenario1 & Scenario2 & Scenario3 & Scenario1 & Scenario2 & Scenario3 & Scenario1 & Scenario2 & Scenario3 \\
\hline 2 & 48,901 & 48,113 & 62,649 & 50,865 & 50,865 & 58,500 & 75.0 & 75.0 & 158.0 \\
\hline 3 & 4990 & 4990 & 4990 & 7870 & 7870 & 7870 & 75.0 & 75.0 & 75.0 \\
\hline 4 & 56,610 & 35,570 & 43,938 & 63,581 & 63,581 & 63,581 & 75.0 & 75.0 & 75.0 \\
\hline 7 & 2677 & 2677 & 2677 & 6358 & 6358 & 6358 & 75.0 & 75.0 & 75.0 \\
\hline 8 & 18,742 & 18,742 & 18,749 & 16,738 & 14,553 & 16,738 & 115.1 & 158.8 & 115.2 \\
\hline 9 & 14,278 & 14,228 & 14,271 & 14,278 & 14,129 & 14,271 & 75.0 & 77.0 & 75.0 \\
\hline
\end{tabular}

Table 5 describes the possible combinations of terminal selections and the ratio of shipments of origin-destination pairs. The pattern that most of O-D pairs have in the base case is S-H-H-S, which is an origin subterminal that is connected to a hub terminal, and the shipments are carried to the other hub terminal for the destination sub terminals. The routing strategy of Scenarios 2 and 3 reduces the number of hub terminals in the path. Consequently, the ratio of S-H-H-S for both scenarios is lower than the base case, while the pattern that has only one hub in the middle of the path (S-H-S, S-H-S, $\mathrm{H}-\mathrm{H}-\mathrm{S}$ ) is more frequently assigned, which tends to be a hub-and-spoke logistic system.

Table 5. The Comparisons of the Possible Combinations of Terminal Selections and the Ratio of Shipments of Origin-Destination Pairs

\begin{tabular}{|c|c|c|c|c|c|}
\hline \multirow{2}{*}{ Path } & \multirow{2}{*}{ Category } & \multicolumn{4}{|c|}{ Scenario } \\
\hline & & Base & 1. Processing Rate & 2. Routing & 3. Complete \\
\hline S-H-H-S & Two hubs & $45.0 \%$ & $45.0 \%$ & $30.9 \%$ & $34.1 \%$ \\
\hline S-H-S & \multirow{3}{*}{ Single hub } & $10.4 \%$ & $10.4 \%$ & $22.9 \%$ & $19.7 \%$ \\
\hline S-H-H & & $16.5 \%$ & $16.5 \%$ & $13.2 \%$ & $13.8 \%$ \\
\hline $\mathrm{H}-\mathrm{H}-\mathrm{S}$ & & $18.6 \%$ & $18.6 \%$ & $15.4 \%$ & $16.5 \%$ \\
\hline H-S & \multirow{3}{*}{ Two points } & $3.3 \%$ & $3.3 \%$ & $5.9 \%$ & $4.8 \%$ \\
\hline S-H & & $0.0 \%$ & $0.0 \%$ & $5.6 \%$ & $4.9 \%$ \\
\hline $\mathrm{H}-\mathrm{H}$ & & $6.3 \%$ & $6.3 \%$ & $6.2 \%$ & $6.2 \%$ \\
\hline \multicolumn{2}{|c|}{ Total } & $100 \%$ & $100 \%$ & $100 \%$ & $100 \%$ \\
\hline
\end{tabular}

From the total traveled distances of the trucks and the number of the assigned truck trips in Table 6 , we also calculate total greenhouse gas emissions. The total GHG $\left(\mathrm{CO}_{2}\right)$ decreases to 82.70 tons per hour in Scenario 3 from the base case at 92.10. The reduced travel distance of both hub-hub trips and sub-hub trips takes a significant portion of the $\mathrm{CO}_{2}$ reductions. The number of truck trips between hub terminals also decreases to 123 at the amount of 10 truck trips per hour, which reduces $\mathrm{CO}_{2}$ from idling of 11-ton high cube trailers. There is also a decline in the number of sub-hub trips from 479 to 418.

Sensitivity analysis aids in understanding how the model solution is affected with a change in its various inputs that might be either external or internal. In [32], the importance of the simulation-based sensitivity analysis is shown by randomly changing selected parameters functioning to logistic facilities. In our research, transportation cost and terminal cost are critical parameters in the optimization, which have a tradeoff relationship. For sensitivity analysis of the two parameters to the proposed model, we vary the transportation cost and terminal processing cost by a linear multiplication from 1 to 3 at intervals of 0.5 , which generates a total of 1600 cases for the simulation analysis. For example, 
a value of multiplication factor 2 implies that the basic transportation cost and distance-based cost of a box are two times more expensive than the base case.

Table 6. The Comparisons of GHG Emission of The Scenarios.

\begin{tabular}{cccccc}
\hline \multirow{2}{*}{ Component } & \multirow{2}{*}{ Link Type } & \multicolumn{4}{c}{ Scenario } \\
\cline { 3 - 6 } & & Base & 1. Processing Rate & 2. Routing & 3. Complete \\
\hline $\begin{array}{c}\text { total travel distance } \\
\text { (kilometers/hour) }\end{array}$ & hub-hub & 22,555 & 22,555 & 20,822 & 20,756 \\
\hline sub-hub & 31,315 & 31,315 & 26,136 & 26,806 \\
\hline the number of truck & hub-hub & 133 & 133 & 119 & 123 \\
\hline $\mathrm{CO}_{2}$ RunEx & sub-hub & 479 & 479 & 437 & 418 \\
(ton/hour) & 11-ton HC trailer & 60.09 & 60.09 & 55.47 & 55.30 \\
\hline $\mathrm{CO}_{2}$ IdleEx & 5-ton box truck & 31.34 & 31.34 & 26.16 & 26.83 \\
(ton/hour) & 5-ton HC trailer & 0.59 & 0.59 & 0.53 & 0.55 \\
\hline \multicolumn{2}{c}{ Total GHG $\left(\mathrm{CO}_{2}\right.$, ton/hour) } & 92.10 & 9.07 & 0.07 & 0.07 \\
\hline
\end{tabular}

Figure 11 visualizes the results of the sensitivity analysis for the proposed method. Figure 11a indicates the relationship between terminal cost and transportation cost. The total cost increases with respect to the price increases. It is noteworthy that the mathematical solution does not provide the optimal solution due to the single pathfinding problem, as mentioned in Section 3.2. However, as indicated in Figure 11a, the iterative bi-level problem provides reliable solutions, which shows a consistent trend of the total costs with increasing the value of associated parameters. From Figure 11a and $11 \mathrm{~b}$, we can observe the continuous points that suddenly increased costs, which are correlated to the maximum processing rate of a hub terminal, $C_{\max }^{a}$. This reaffirms the tradeoff relationship between the two parameters. As transportation costs increase, more shipments go to a closer terminal. Then, the shipments arrival rate becomes higher than $C_{\text {max }}^{a}$, consequently, terminal cost suddenly increases. Figure 11c supports the findings of tradeoff relationships. Although the unit transportation cost increases, the total transportation cost is stable since the proposed bi-level program minimizes transportation costs by routing shipments to terminals to save transportation costs. Figure $11 \mathrm{~d}$ is the result of $\mathrm{CO}_{2}$ emissions. Since total travel distances are associated with the $\mathrm{CO}_{2}$ emission, $\mathrm{CO}_{2}$ emission decreases with higher transportation costs.

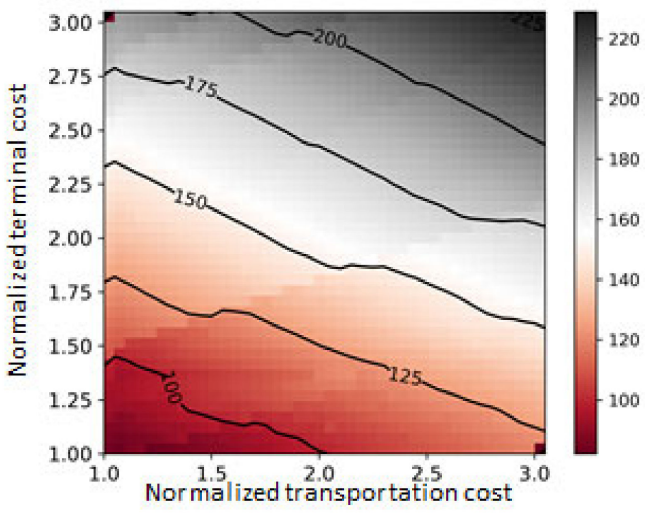

(a)

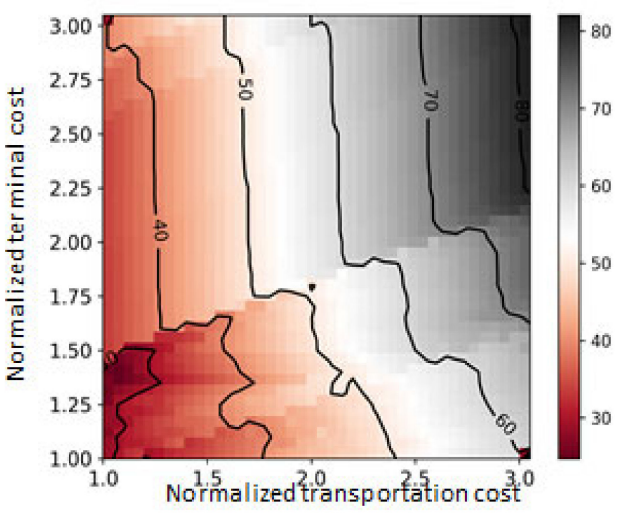

(b)

Figure 11. Cont. 


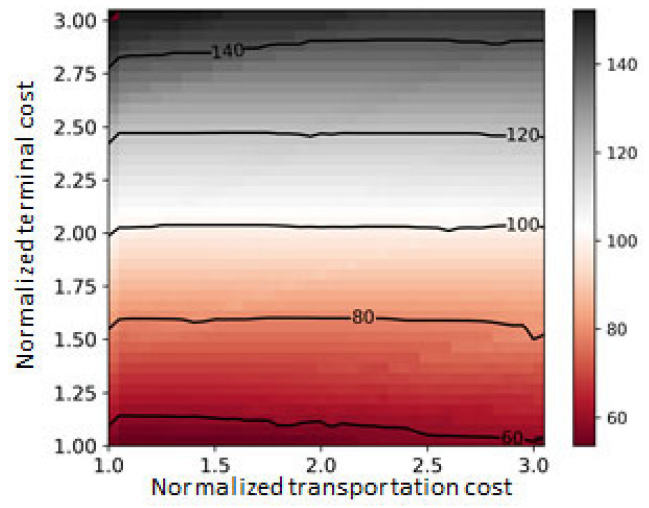

(c)

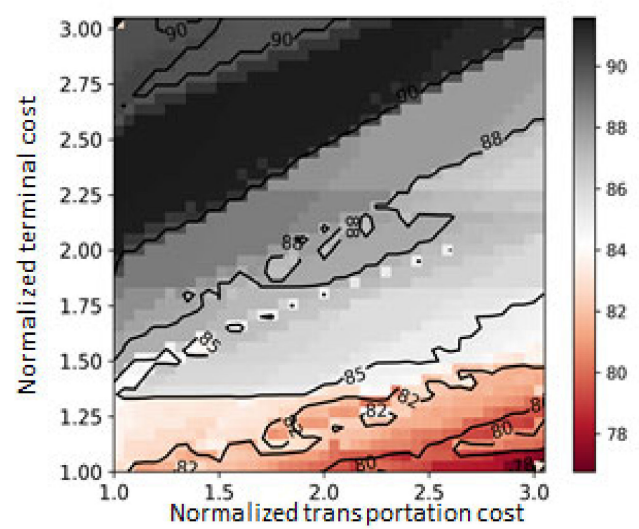

(d)

Figure 11. The Results of The Sensitivity Analysis. (a) Total cost (Million KRW/h), (b) Total terminal cost (Million KRW/h), (c) Total transportation cost (Million KRW/h), (d) Total Co2 emissions (T/h).

\section{Discussion}

A number of studies in the literature show the importance of integrating terminal management with fleet assignment problems since those elements can be mutually effective $[7,10,14,15,18,31,33,34]$. Terminal size and location problems with minimized transport costs or greenhouse gas emissions are one such example. In addition to the existing terminals, some logistic managers might wish to add completely new terminals on a certain location or choose to relocate the terminal. Building a new terminal is not trivial and relocating terminals can be even more challenging since those solutions involve complex decision-making processes with considerations of land-use policy and land price. Furthermore, current parcel shipping services experience dynamically changing spatiotemporal distribution of demand that massive infrastructure investment that takes place over a long period of time cannot address. Thus, sustainable logistics requires a smart and flexible utilization of the existing supply.

This study addresses the inherent limitations of logistics management. A smart logistics company operating a parcel shipping service may prefer a collaboration between a terminal manager and a routing manager. We assume that a smart logistics company is capable of managing shipments data via an open communication technology such as blockchain [18]. This enables the terminal manager to interact with a fleet manager to optimize the logistic system. A terminal manager wishing to utilize existing facilities efficiently might avoid the system due to marginal costs arising from unscheduled congestion of inner terminals. Consequently, they first try to control the processing rate as long as the terminal's capacity is maintained. For instance, a terminal manager plans to increase the processing rates of shipments by applying automatic processing machinery or adding temporary workers if congestion is expected. Then, the manager requests the route manager to plan an itinerary and fleet types of shipments to minimize both terminal costs and transport costs as well as gas emissions. The route manager obtains shipment data to identify the minimum total cost itinerary of shipments, then provides the terminal manager with the itinerary, who then recalculates the operation plan of terminals.

We propose a smart logistic system design by formulating a bi-level problem that reflects the behavior of the collaborative consumption of existing supply between a terminal manager and a fleet router. It is reasonable for parcel shipping companies that own terminals and operate fleet assignment together, to assume these collaborations for better efficiency. The case study of a parcel delivery logistic system in Korea also shows that cooperation between two managers reduces total travel cost and greenhouse gas emissions significantly. Our comparative analysis indicates that a single approach, such as terminal operations and routing planning, can also improve the overall efficiency of a system. Terminal operations (processing rate control) with current routing strategy 
reduces total cost approximately $5.8 \%$. Without the processing rate control, only routing planning has limited effectiveness where the reduction of total cost is only about $0.53 \%$. This is because the simple route plan may have a bouncing effect on the arrival rate of shipments, meaning that some other terminals, currently uncongested, may overflow when a fleet manager sends shipments to the terminals. The manager in our integrated model undertakes an iterative process where they increase the service rate of a terminal, and the route manager finds a minimum cost path until they find the solution. This iterative process is modeled in bi-level programming to find the optimal allocation of shipments and recommended processing increases of each terminal. This finding also supports the importance of integrated logistics operations, which have been discussed in other research efforts.

Sensitivity analysis shows that the proposed bi-level approach can offer a reliable and stable solution with the increased transport costs and terminal costs. The results of the sensitivity analysis imply that the proposed method can control the tradeoff relationship between those two cost elements. In the situation where transportation costs increase, the proposed method minimizes total cost by calculating an itinerary that minimizes transport costs; consequently, the total terminal costs increase due to the growth of shipments to near hub terminals. Another finding is that the minimized total transport costs in the higher unit cost of transport can also decrease the total $\mathrm{CO}_{2}$ emissions.

\section{Conclusions}

The efficiency of a logistics system can be improved by optimization models. This study designs a method to manage terminals operations and routing strategy efficiently. The result of the case study implies that the smart usage of hub terminal capacity improves the efficiency of a logistic system. In addition, green logistics should incorporate the collaboration between terminal management and routing strategy to enhance efficiency and sustainability.

In addition to the findings, this paper includes academic contributions to existing research by incorporating costs related to hub delay into the integrated model of both hub terminal and routing strategy. To capture congestion effects of hub delays with respect to the excessive demand, our study employs queuing theory that estimates average waiting time under shipment density and derives the unit processing cost of a hub terminal. We applied an M/M/1 queue model, whose arrivals are assumed to sampled from a Poisson distribution, for a mathematical model that is also used in [5]. However, there are other candidates for the choice of the stochastic distribution of arrivals and service times $[7,35,36]$. Accordingly, our future research efforts aim to identify the best queue model for the processing cost to better capture actual impacts of arrival rate and processing rate on waiting time. Furthermore, our method simplifies terminal operation cost, which is supposed to relate with many factors such as loading, unloading bulk, sorting, processing, batch, and so on.

This research also has contributions to solution methodology. By interpreting processing activities of a terminal cost as elements of a graph, we transform the mathematical programming problem into a minimum pathfinding problem, which solves the non-linear mixed-integer programming in reasonable computational time. In addition, this network solution approach allows us to combine the route solution into the estimation of greenhouse gas emissions.

In this study, we assume that all shipments of a local sub terminal are assigned to a single path, which is modeled for a collaboration between a terminal operator and a fleet manager; thus, the solution cannot be equilibrated since an updated path could induce marginal cost onto the assigned terminals. However, current research shows the potential to model collaborations between multiple participants, which enables a system to find the system-optimum solution. The system optimum (SO) solution can be computed by applying the traditional system optimum assignment technique, which finds an equilibrated solution in a marginal cost function. The $\mathrm{SO}$ solution might bring various alternatives where its properties (e.g., time and cost) are not identical; consequently, a logistics company can consider various preferences of participants in their delivery service design.

In addition, future research should incorporate the detailed components of a cost function, which we assumed as a single entity in transportation and terminal costs. For example, transportation 
costs might be affected by legal constraints, such as a driver's maximum working hours, resting behaviors, right of way, and parking availability during legally defined off-time. Moreover, for the actual implementation, it is necessary to identify the shipments arrival distribution, which we assumed to be a Poisson distribution. Although the Poisson distribution assumption offers a convenient mathematical solution, the shipment arrivals could be distributed differently. Furthermore, the model can be more accurate if we consider an actual shipment handling process in a terminal, such as inventory holding [1,37], sorting [15,19], and loading and unloading [7]. Our study conducted a sensitivity analysis to quantify the tradeoff relationship between transport costs and terminal costs. A more comprehensive scenario-based sensitivity analysis can be envisioned with various parameters and other assumptions such as shipments arrival distributions and fleet routers' behavior.

Author Contributions: Conceptualization, D.N. and M.P.; methodology, D.N. software, D.N.; validation, D.N. and M.P.; resources, M.P.; data curation, M.P.; writing-Original draft preparation, D.N.; writing-Review and editing, D.N. and M.P.; visualization, D.N.; supervision, M.P.; project administration, D.N. and M.P. All authors have read and agreed to the published version of the manuscript.

Funding: This work was supported by Institute of Information and Communications Technology Planning and Evaluation (IITP) grant funded by the Korea government (MSIT) (2020-0-01389, Artificial Intelligence Convergence Research Center (Inha University))

Conflicts of Interest: The authors declare no conflict of interest.

\section{References}

1. Campbell, J.F. Designing logistics systems by analyzing transportation, inventory and terminal cost tradeoffs. J. Bus. Logist. 1990, 11, 159-179.

2. Daganzo, C.F. Logistics Systems Analysis, 4th ed.; Springer: Berlin/Heidelberg, Germany, 2005.

3. Munisamy, S. Timber terminal capacity planning through queuing theory. Marit. Econ. Logist. 2010, 12, 147-161. [CrossRef]

4. Trappey, A.J.C.; Trappey, C.V.; Fan, C.Y.; Hsu, A.P.T.; Li, X.K.; Lee, I.J.Y. IoT patent roadmap for smart logistic service provision in the context of Industry 4.0. J. Chin. Inst. Eng. 2017, 40, 593-602. [CrossRef]

5. Masek, J.; Camaj, J.; Nedeliakova, E. Application the Queuing theory in the warehouse optimization. World Acad. Sci. Eng. Technol. Int. J. Soc. Behav. Educ. Econ. Bus. Ind. Eng. 2015, 9, 3713-3717.

6. Allen, A.O. Probability, Statistics, and Queueing Theory; Academic Press: Cambridge, MA, USA, 2014.

7. Ishfaq, R.; Sox, C.R. Design of intermodal logistics networks with hub delays. Eur. J. Oper. Res. 2012, 220, 629-641. [CrossRef]

8. Taniguchi, E.; Noritake, M.; Yamada, T.; Izumitani, T. Optimizing the size and location of logistic terminals. IFAC Transp. Syst. 1997, 30, 741-746. [CrossRef]

9. Kostrzewski, M.; Varjan, P.; Gnap, J. Solutions Dedicated to internal logistics 4.0. In Sustainable Logistics and Production in Industry 4.0; Springer: Berlin/Heidelberg, Germany, 2020; pp. 243-262.

10. Tavasszy, L.A.; Ruijgrok, K.; Davydenko, I. Incorporating logistics in freight transport demand models: State-of-the-Art and research opportunities. Transp. Rev. 2012, 32, 203-219. [CrossRef]

11. Fischer, M.J.; Outwater, M.L.; Cheng, L.L.; Ahanotu, D.N.; Calix, R. Innovative framework for modeling freight transportation in los angeles county, california. Transp. Res. Rec. 2005, 1, 105-112. [CrossRef]

12. Masaeli, M.; Alumur, S.A.; Bookbinder, J.H. Shipment scheduling in hub location problems. Transp. Res. Part B Methodol. 2018, 115, 126-142. [CrossRef]

13. Macaulay, J.; Buckalew, L.; Chung, G. Internet of Things in Logistics; DHL Trend Research: Troisdorf, Germany, 2015.

14. Yang, X.; Bostel, N.; Dejax, P. A MILP model and memetic algorithm for the Hub Location and Routing problem with distinct collection and delivery tours. Comput. Ind. Eng. 2019, 135, 105-119. [CrossRef]

15. Lee, J.H.; Moon, I. A hybrid hub-and-spoke postal logistics network with realistic restrictions: A case study of Korea Post. Expert Syst. Appl. 2014, 41, 5509-5519. [CrossRef]

16. Mahesh, S.; Ramadurai, G.; Nagendra, S.M.S. On-board measurement of emissions from freight trucks in urban arterials: Effect of operating conditions, emission standards, and truck size. Atmos. Environ. 2019, 212, 75-82. [CrossRef] 
17. Inkinen, T.; Hämäläinen, E. Reviewing truck logistics: Solutions for achieving low emission road freight transport. Sustainability 2020, 12, 6714. [CrossRef]

18. Tan, B.Q.; Wang, F.; Liu, J.; Kang, K.; Costa, F. A blockchain-based framework for green logistics in supply chains. Sustainability 2020, 12, 4656. [CrossRef]

19. Hao, J.; Shi, H.; Shi, V.; Yang, C. Adoption of automatic warehousing systems in logistics firms: A technology-organization-environment framework. Sustainability 2020, 12, 5185. [CrossRef]

20. Mikić, M.; Todosijević, R.; Urošević, D. Less is more: General variable neighborhood search for the capacitated modular hub location problem. Comput. Oper. Res. 2019, 110, 101-115. [CrossRef]

21. EMFAC. EMFAC2017 Volume III-Technical Documentation. Available online: https://ww3.arb.ca.gov/msei/ downloads/emfac2017-volume-iii-technical-documentation.pdf (accessed on 20 August 2020).

22. Epic Regional Climate Action Planning Framework: Technical Appendix I, Ghg Inventories, Projections, and Target Selection. Available online: https://www.sandag.org/uploads/cap/ReCapTAI.pdf (accessed on 20 September 2020).

23. SCAG Connected SoCal Plan. Available online: https://www.connectsocal.org/Documents/Adopted/ fConnectSoCal-Plan.pdf (accessed on 21 September 2020).

24. SCAG. Mobility Go Zone E Pricing Feasibility Study; SCAG: Los Angeles, CA, USA, 2019.

25. Hiller, F.S.; Hiller, M.S. Introduction to Management Science: A Modeling and Case Studies Approach With Spreadsheets, 6th ed.; Mcgraw-Hill College: New York, NY, USA, 2019.

26. El-Taha, M.; Stidham, S. Little's formula and extensions. In Sample-Path Analysis of Queueing Systems; Springer: Boston, MA, USA, 1999.

27. Glorot, X.; Bordes, A.; Bengio, Y. Deep Sparse Rectifier Neural Networks. In Proceedings of the 14th International Conference on Artificial Intelligence and Statistics (AISTATS ‘11), Fort Lauderdale, FL, USA, 11-13 April 2011; Volume 15, pp. 315-323.

28. Ben-Ayed, O.; Blair, C.E. Computational difficulties of bilevel linear programming. Oper. Res. 1990, 38, 556-560. [CrossRef]

29. Bard, J.F. Some properties of the bilevel programming problem. J. Optim. Theory Appl. 1991, 68, 371-378. [CrossRef]

30. Ko, C.S.; Moon, I.; Park, M.; Chung, B. Analysis on the Size of Hub Terminals and Operational Structure of Logistic Managements; Korean Society of Transport Policy and Economics: Incheon, Korea, 2017.

31. Özener, O.Ö. Solving the integrated shipment routing problem of a less-than-truckload carrier. Discret. Appl. Math. 2019, 252, 37-50. [CrossRef]

32. Kostrzewski, M. Sensitivity analysis of selected parameters in the order picking process simulation model, with randomly generated orders. Entropy 2020, 22, 423. [CrossRef]

33. Behdani, B.; Fan, Y.; Wiegmans, B.; Zuidwijk, R. Multimodal schedule design for synchromodal freight transport systems. Eur. J. Transp. Infrastruct. Res. 2016, 16, 424-444. [CrossRef]

34. Huber, S.; Klauenberg, J.; Thaller, C. Consideration of transport logistics hubs in freight transport demand models. Eur. Transp. Res. Rev. 2015, 7, 32. [CrossRef]

35. Jackson, J.R. Jobshop-like queueing systems. Manage. Sci. 1963, 10, 131-142. [CrossRef]

36. Gordon, W.J.; Newell, G.F. Closed queuing systems with exponential servers. Oper. Res. 1967, 15, $254-265$. [CrossRef]

37. Minken, H.; Johansen, B.G. A logistics cost function with explicit transport costs. Econ. Transp. 2019, 19, 100116. [CrossRef]

(C) 2020 by the authors. Licensee MDPI, Basel, Switzerland. This article is an open access article distributed under the terms and conditions of the Creative Commons Attribution (CC BY) license (http://creativecommons.org/licenses/by/4.0/). 